\title{
Diagnóstico patológico da micoplasmose respiratória murina em Rattus norvegicus
}

\author{
Pathological diagnosis of murine respiratory mycoplasmosis in Rattus norvegicus \\ Maria Lucia Barreto ${ }^{1}$, Elmiro Rosendo do Nascimento르. Rosaura Presgrave ${ }^{3}$, Carlos Augusto de Martino \\ Campos $^{4}$, Maria da Graça Fichel do Nascimento ${ }^{5}$ \& Gilberto Brasil Lignon ${ }^{6}$
}

\begin{abstract}
RESUMO
O uso de animais em experimentos biomédicos com padrão genético e sanitário definido fornece ao pesquisador, modelos importantes para a compreensão de mecanismos biológicos. Entretanto, nesses modelos os ratos podem se infectar por agentes patogênicos, como os Micoplasmas, os quais introduzidos na criação, afetam a produção e os resultados experimentais. Este estudo foi desenvolvido em ratos, positivos para Mycoplasma pulmonis, obtidos de dois biotérios, um em Niterói e outro no Rio de Janeiro. Um foi classificado como convencional controlado e o outro como convencional. O objetivo foi caracterizar as lesões encontradas em pulmões e traquéias de animais que apresentavam sintomas de doença respiratória e baixa produtividade. No biotério convencional controlado foram necropsiados 16 ratos da linhagem WistarFurth e no biotério convencional, 12 ratos da linhagem Hooded Lister. As amostras de pulmão, traquéia e útero foram submetidas a análise anatomopatológica. No exame anatomopatológico, os animais estudados apresentavam graus variados de lesões, basicamente, nos pulmões e na traquéia. Dentre os diferentes graus de lesões macroscópicas observados nesses órgãos, as lesões discretas (46,43\% e $25,00 \%$, respectivamente) e acentuadas (46,43\% e 32,15\%, respectivamente) foram as mais encontradas em ambos os órgãos enquanto que, no exame microscópico, as lesões mais encontradas foram as acentuadas nos pulmões $(64,70 \%)$ e, discretas $(41,18 \%)$ e moderadas $(41,18 \%)$ nas traquéias. Para os padrões sanitários mencionados e, na ausência de outros métodos, o exame anatomopatológico pode ser utilizado para o diagnóstico da Micoplasmose Respiratória Murina.
\end{abstract}

Descritores: Mycoplasma pulmonis, ratos, Micoplasmose Respiratória Murina.

\begin{abstract}
Animals of known genetic and sanitary backgrounds are important models for use in biomedical experiments for the study of biological mechanisms. However, rats as one of these models can become infected by specific pathogens, such as Mycoplasma sp., which may compromise animal production and experimental results. This study was conducted on rats positive for Mycoplasma pulmonis from two premises located, respectively, in Niterói and Rio de Janeiro, RJ-Brazil. One was classified as conventional controlled and the other, conventional. The main objective was to characterize the lesions in trachea and lungs of infected animals, which presented symptoms of respiratory disease and low rate of production. In the conventional controlled premises, 16 rats of Wistar-Furth strain were necropsied while in the conventional premises, the necropsies were done on 12 rats of Hooded Lister strain. Gross examination and collection of samples for histopathological examination were performed in the lungs, trachea and uterus of the studied rats. Among the different degree of gross lesions in lungs and trachea, the discrete $(46.43 \%$ and $25.00 \%$, respectively), and the accentuated pattern $(46.43 \%$ and $32.15 \%$ respectively) were mostly found in both organs. Under microscopy, the accentuated lesions were mostly present in the lungs $(64.70 \%)$ while in the trachea they were split into discrete (41.18\%) and moderated (41.18\%). For these mentioned sanitary patterns, and in the absence of other methods, the pathologic examination was found to be useful for the diagnosis of Murine Respiratory Mycoplasmosis.
\end{abstract}

Key words: Mycoplasma pulmonis, rats, Murine Respiratory Mycoplasmosis.

${ }^{1}$ Núcleo de Animais de Laboratório (NAL). Universidade Federal Fluminense (UFF). ${ }^{2}$ Departamento de Patologia e Clínica Veterinária, Faculdade de Veterinária - UFF. ${ }^{3}$ FIOCRUZ/INCQS, Rio de Janeiro, RJ. ${ }^{4}$ GIM/NAL - UFF. ${ }^{5}$ Embrapa Agroindústria de Alimentos, Rio de Janeiro, RJ. ${ }^{6}$ Embrapa Agrobiologia, Seropédica, RJ. CORRESPONDÊNCIA: M. L. Barreto [e-mail: lucia@vm.uff.br] Morro do Valonguinhos S/ N (Centro); 24020-007 Niterói, RJ - Brasil. 


\section{INTRODUÇÃO}

O uso de animais em experimentos biomédicos com padrão genético e sanitário definido data do início do século XX [13]. Entretanto, nesses modelos, os ratos podem se infectar por agentes patogênicos que afetam a produção e os resultados experimentais.

O Mycoplasma pulmonis é o agente etiológico da micoplasmose respiratória murina (MRM) que acomete com freqüência animais de laboratório, principalmente ratos e camundongos [7,14-16,23].

A MRM tem sido encontrada em colônias convencionais e em colônias com barreiras $[8,10]$. Em sua forma inaparente, pode produzir interferências nos resultados experimentais afetando significativamente os dados obtidos [7,17,29]. A transmissão do $M$. pulmonis ocorre na forma vertical ou horizontal $[22,25,30]$. A aderência do micoplasma às células hospedeiras produz lesões pelo uso dos componentes celulares e/ou liberação de substâncias metabólicas tóxicas $[3,14,18,20,24]$.

Nos biotérios brasileiros, o diagnóstico da MRM sempre foi dado, presuntivamente, através dos sintomas e aspectos macroscópicos dos pulmões. Entretanto, Mycoplasma spp já foram isolados de ratos acometidos de pneumonia ou de processos inflamatórios articulares [26]. Sendo posteriormente, $M$. pulmonis e $M$. arthritidis, isolados de ratos e camundongos oriundos de colônias convencionais, em São Paulo [31].

No Rio de Janeiro, embora em muitos Biotérios já se tenham encontrado lesões macroscópicas sugestivas de micoplasmose, o trabalho de isolamento e caracterização ocorreu pela primeira vez em 1996 [2], sendo o teste de ELISA desenvolvido e utilizado a seguir [4].

Este trabalho teve como objetivo a caracterização das lesões de MRM, com ênfase às manifestações respiratórias dessa micoplasmose.

\section{MATERIAIS E MÉTODOS}

\section{Animais}

Foram utilizados 28 ratos de dois biotérios do Estado do Rio de Janeiro, sendo 16 de um biotério de criação convencional controlado e 12 de um biotério convencional.

No biotério convencional controlado foram selecionados 16 animais (10 fêmeas e seis machos) da linhagem Wistar-Furth com idades entre seis e 12 meses, que vinham apresentando sintomas respiratórios. Embora tenha sido coletado material do ouvido médio, através de lavagem, de parte desses animais, apenas um deles tinha sinais de labirintite. No biotério convencional, foram selecionadas 12 fêmeas da linhagem Hooded Lister, com idades entre 10 e 12 meses, que também apresentavam sintomas de doença respiratória como espirros, secreção nasal e ocular. Os mais afetados apresentavam perda de peso, pêlos arrepiados e baixa produtividade.

\section{Coleta das amostras}

Os animais, após anestesia com pentobarbital sódico $(0,06 \mathrm{mg} / \mathrm{g})$ [6], foram sangrados, por via intracardíaca, usando-se tubo vacuntainer ${ }^{\circledR}$ para a obtenção do soro. Posteriormente foram sacrificados com overdose do anestésico e necropsiados em condições assépticas. Para cultivo de micoplasma foram coletados fragmentos de pulmões e traquéia, lavados de traquéia e ouvido dos animais do biotério convencional controlado e fragmentos de pulmões, traquéia, útero, ovário e swab de orofaringe dos animais do biotério convencional.

Para o exame histopatológico, foram utilizados fragmentos de traquéia, pulmão e útero os quais foram fixados em formol a $10 \%$ tamponado.

\section{Anatomopatologia}

Macroscopia: As lesões macroscópicas foram descritas para todos os órgãos examinados. As lesões macroscópicas encontradas nesses órgãos foram graduadas da seguinte forma: Pulmão - (0), sem lesão; (1), lobo de consistência firme e cor vermelho-escura (hepatização vermelha); (2), lobo de consistência firme e cor vermelho-escura (hepatização vermelha) e áreas em depressão de cor acinzentada; (3), lobo de consistência firme e cor cinza-escura (hepatização cinza), áreas em depressão de cor acinzentada e nódulos amarelos de diferentes tamanhos (broncoectasia). Traquéia - (0), sem lesão; (1), presença discreta de exudato límpido; (2) presença moderada de exudato, límpido; (3) presença acentuada de exudato mucopurulento.

Microscopia: Após a fixação em formol a 10\% tamponado, todos os tecidos foram clivados, embebidos em parafina, cortados $(5 \mathrm{~mm})$ e corados por 
hematoxilina e eosina (HE), de acordo com protocolo padrão. Os tecidos foram examinados, microscopicamente, para verificação da presença de lesões compatíveis com a MRM, as quais foram fotografadas. A graduação das lesões microscópicas foi feita somente para pulmões e traquéia [28]: Pulmão - (0), sem lesão; (1), leve hiperplasia do tecido linfocitário peribronquial (BALT) ou leve infiltrado linfocitário peri-vascular; (2), moderada hiperplasia do tecido linfocitário peribronquial (BALT) e/ou moderado infiltrado linfocitário perivascular; (3), acentuada hiperplasia do tecido linfocitário peribronquial (BALT) e acentuado infiltrado linfocitário peri-vascular e bronquectasia. Traquéia (0), sem lesão; (1) discreto infiltrado linfocitário na submucosa traqueal; (2) moderado infiltrado linfocitário na submucosa traqueal; (3) intenso infiltrado linfocitário na submucosa traqueal.

\section{Análise estatística}

As diferenças de proporções entre o diagnóstico macroscópico e microscópico para os diferentes graus de lesões foram feitas pelo teste de Qui-quadrado [21].

\section{RESULTADOS}

Os animais examinados apresentavam, como sintomas clínicos mais evidentes, perda de peso, prurido cutâneo intenso, pêlos arrepiados e espirros freqüentes. Adicionalmente, foram vistos sinais de labirintite, no biotério convencional controlado e, baixa produtividade no biotério convencional.

Os diferentes graus de lesões macroscópicas observadas nos pulmões e na traquéia dos 28 animais estudados são mostrados na Tabela 1 e nas Figuras $1 \mathrm{~A}$ e $1 \mathrm{~B}$, respectivamente. As lesões discretas e acentuadas foram as mais encontradas em ambos os órgãos. Nos pulmões foram encontradas 46,43\% (13/ 28) de lesões discretas e acentuadas. Em traquéias, o índice de lesões acentuadas foi de 32,15\% (9/28), o de lesões moderadas foi de $3,6 \%(1 / 28)$ e o de lesões discretas foi de $25,00 \%$ (7/28).

As lesões encontradas nos pulmões, em um ou mais lobos, consistiam de áreas firmes com coloração variando do vermelho escuro (hepatização pulmonar) ao acinzentado e nódulos amarelados de diferentes tamanhos. Nas traquéias foram encontradas quantidades variáveis de muco, às vezes translúcido e às vezes mais esbranquiçado. Cinco animais apresentaram exudato claro no útero.

Os resultados da análise microscópica encontram-se na Tabela 1 e nas Figuras 2A e 2B. Dos 28 ratos apenas 17 foram analisados microscopicamente e todos os animais analisados tinham lesões macroscópicas no pulmão. O coeficiente de lesões acentuadas, encontrado nos pulmões $(64,70 \%)$ foi maior do que o das traquéias $(17,64 \%)$.

Em 35,30\% dos pulmões foram encontradas lesões moderadas que se caracterizavam por moderada hiperplasia do tecido linfocitário peribronquial (BALT) (Figura 3A) e/ ou moderado infiltrado linfocitário perivascular. Em 64,70\% dos pulmões as lesões eram acentuadas e caracterizavam-se por intensa hiperplasia do tecido linfocitário peribronquial (BALT) (Figura 3B) e acentuado infiltrado linfocitário peri-vascular e broncoectasia (Figura 3C). Em 41,18\% das traquéias analisadas foram encontradas lesões discretas caracterizadas por um leve infiltrado linfocitário na submucosa traqueal (Figura 4A). A mesma proporção de traquéias $(41,18 \%)$ mostrou lesões moderadas e apresentando infiltrado linfocitário moderado na submucosa traqueal (Figura 4B). Em 17,64\% das traquéias as lesões eram acentuadas com infiltrado linfocitário intenso na submucosa (Figura 4C) e perda de cílios. Em 25\% (3/ 12) dos úteros analisados no biotério convencional, observou-se discreto infiltrado de polimorfonucleares.

Tabela 1. Graus de Lesões Respiratórias (pulmões e traquéia) nos Ratos Estudados.

\begin{tabular}{|c|c|c|c|c|c|c|c|c|c|c|c|c|}
\hline \multirow{4}{*}{$\begin{array}{c}\text { Graus } \\
1\end{array}$} & \multicolumn{12}{|c|}{ Lesões respiratórias } \\
\hline & \multicolumn{6}{|c|}{ Macroscópica } & \multicolumn{6}{|c|}{ Microscópica } \\
\hline & \multicolumn{2}{|c|}{ Pulmão } & \multicolumn{2}{|c|}{ Traquéia } & \multicolumn{2}{|c|}{ Ambos } & \multicolumn{2}{|c|}{ Pulmão } & \multicolumn{2}{|c|}{ Traquéia } & \multicolumn{2}{|c|}{ Ambos } \\
\hline & $02 / 28$ & $(7,14)^{*}$ & $11^{* * / 28}$ & $(39,29)$ & $13 / 28$ & $(46,42)$ & $00 / 17$ & $(0,00)$ & $00 / 17$ & $(0,00)$ & $00 / 17$ & $(0,00)$ \\
\hline 2 & $13 / 28$ & $(46,43)$ & $07 / 28$ & $(25,00)$ & $20 / 28$ & $(71,42)$ & $00 / 17$ & $(0,00)$ & $07 / 17$ & $(41,18)$ & $7 / 17$ & $(41,18)$ \\
\hline 3 & $00 / 28$ & $(0,00)$ & $01 / 28$ & $(3,60)$ & $01 / 28$ & $(3,60)$ & $06 / 17$ & $(35,30)$ & $07^{*} / 17$ & $(41,18)$ & $13 / 17$ & $(76,47)$ \\
\hline 4 & $13^{*} / 28$ & $(46,43)$ & $09 / 28$ & $(32,15)$ & $22 / 28$ & $(78,27)$ & $11^{*} / 17$ & $(64,70)$ & $03^{*} / 17$ & $(17,64)$ & $14 / 17$ & $(82,35)$ \\
\hline
\end{tabular}



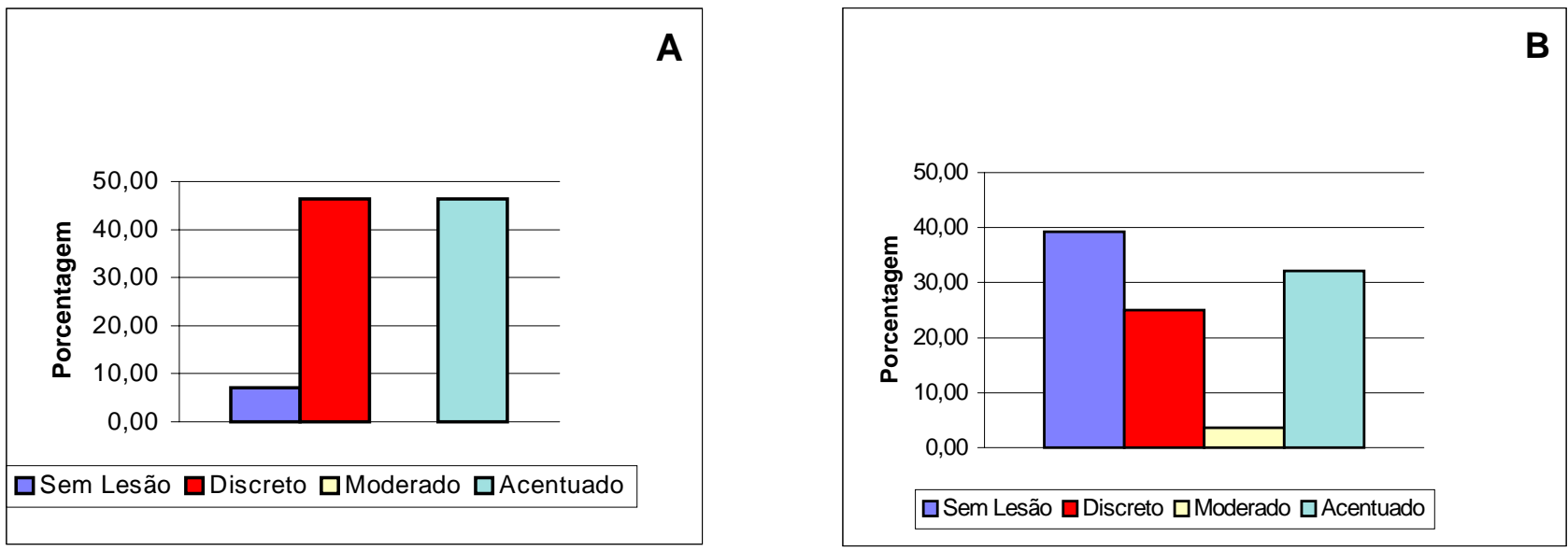

Figura 1. Graus de lesões Macroscópicas Observadas no Pulmões (A) e na Traquéia (B).
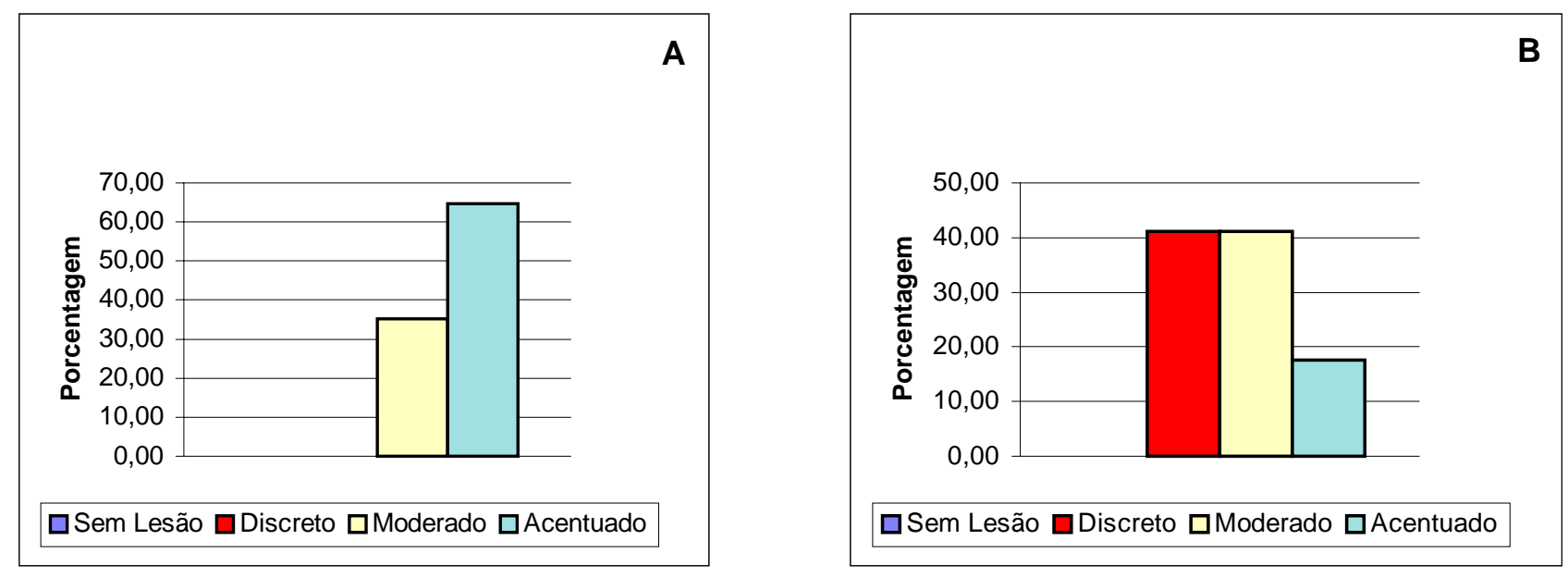

Figura 2. Graus de lesões Microscópicas Observadas nos Pulmões (A) e na Traquéia (B).

Em relação as lesões respiratórias, irrestritamente, aos pulmões ou traquéias (Tabela 1), as proporções entre os graus de lesões utilizados para o diagnóstico pela macroscopia e microscopia diferiram significativamente $(\mathrm{p} \leq 0,01)$. Sendo a maior contribuição do Qui-quadrado observado para o grau acentuado seguido pelo discreto e moderado.

Os mesmos espécimes aqui estudados foram submetidas, aos testes de isolamento [1] e ELISA [4], com vistas ao diagnóstico etiológico, sendo todos os resultados positivos para Mycoplasma pulmonis.

\section{DISCUSSÃO}

Os animais utilizados neste trabalho eram provenientes de biotérios convencionais e apresentavam sintomatologia sugestiva de MRM, conforme descrito $[5,12,14,19]$. Como este trabalho teve por objetivo a caracterização das lesões, não houve necessidade de um número exaustivo de animais, uma vez que a prevalência dessa doença em biotérios convencionais é de $100 \%$ [11]. Neste caso o número de animais utilizados para o diagnóstico satisfez as exigências epidemiológicas [21].

As lesões macro e microscópicas encontradas estão de acordo com a descrição feita anteriormente $[5,12,14]$. As características genéticas, a idade, fatores ambientais [28] e a cepa do M. pulmonis [11] podem ter influenciado as lesões histopatológicas encontradas. Segundo outros autores $[9-11,28]$ as lesões macroscópicas são contraditórias mesmo em animais convencionais e as lesões microscópicas podem ser encontradas quando não há lesões macroscópicas [5,9]. Por estes motivos, os resultados da histopatologia permitem o diagnóstico presuntivo, que deve ser confirmado por isolamento do agente e/ou 


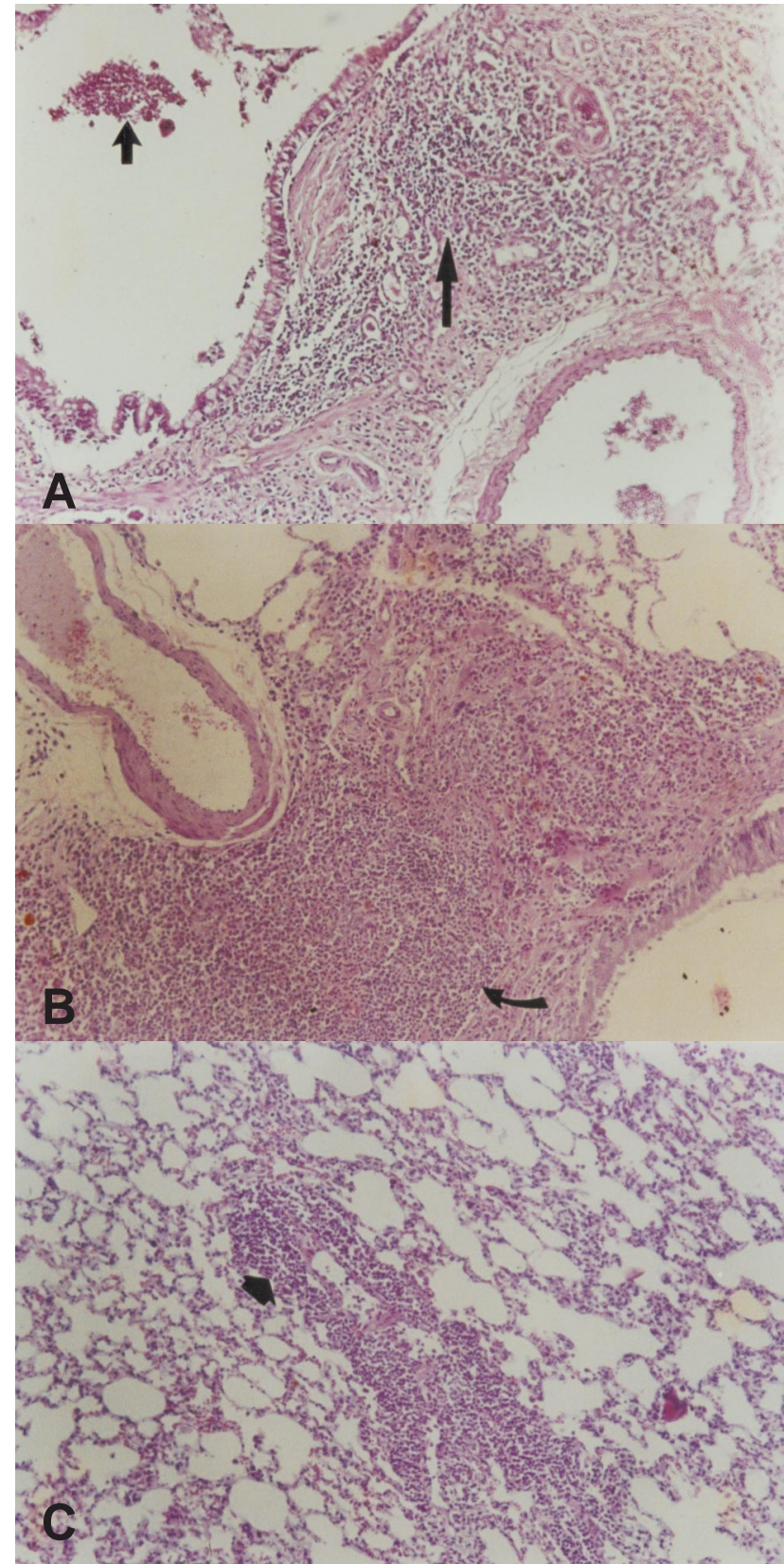

Figura 3. Aspecto histológico do pulmão mostrando a presença de: [A] moderada hiperplasia do tecido linfocitário peribronquial - BALT (seta longa); exsudato de polimorfonucleares na luz dos brônquios (seta curta). HE $(100 \mathrm{x})$. [B] acentuada hiperplasia do tecido linfocitário peribronquial - BALT (seta). HE. (100x). [C] acentuado infiltrado linfocitário perivascular (seta). HE. (100x).

testes sorológicos, embora, neste trabalho, a análise histopatológica tenha mostrado $100 \%$ de sensibilidade, quando comparado com $95 \%$ obtido no ELISA [4] e $57,14 \%$ obtido no isolamento [1]. Este coeficiente

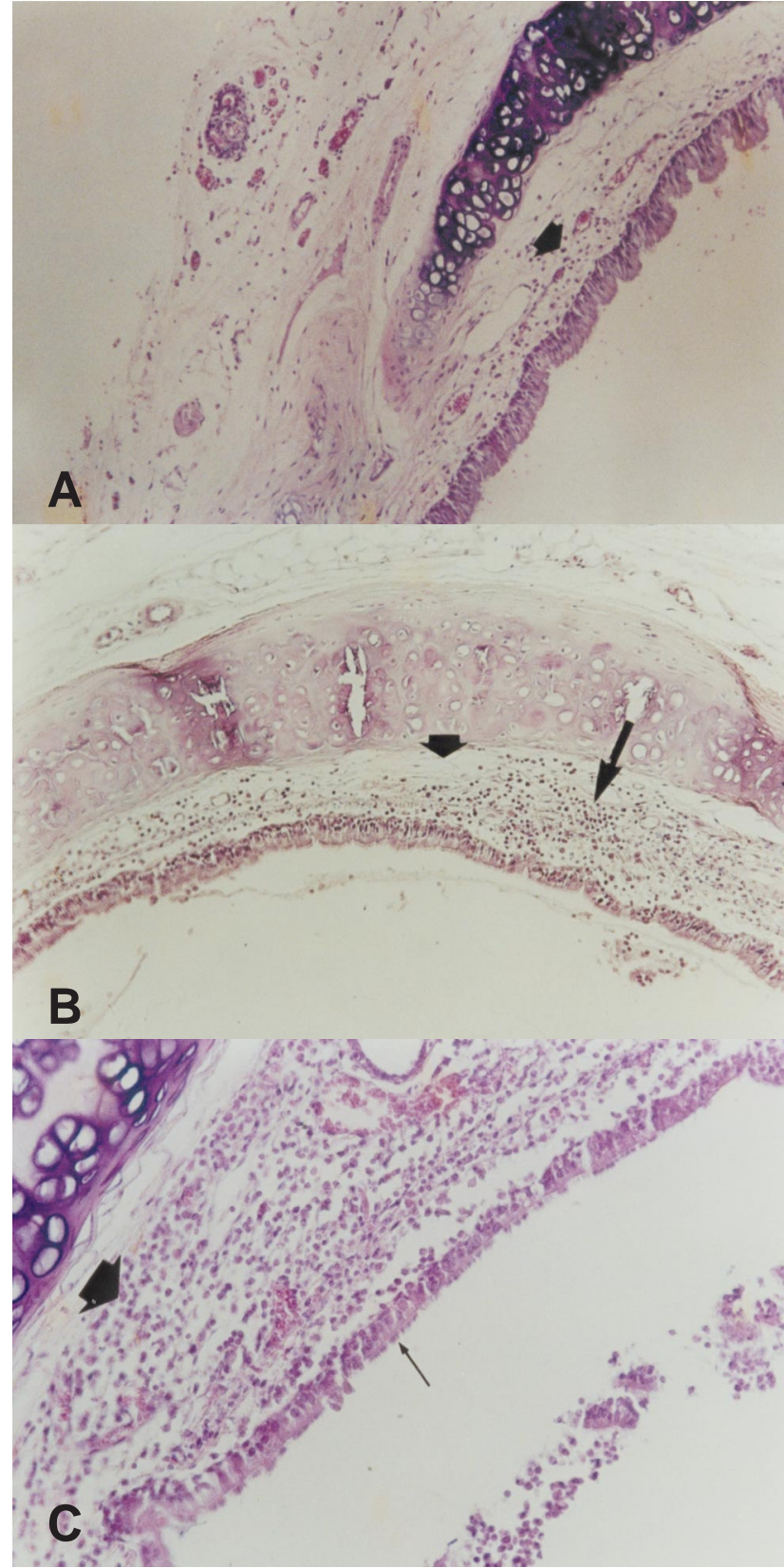

Figura 4. Aspecto histológico da traquéia mostrando a presença de: $[\mathrm{A}]$ discreto infiltrado linfocitário na submucosa traqueal (seta). HE (100 x). [B] moderado infiltrado linfocitário (seta longa) e edema na submucosa traqueal (seta curta). HE $(100 \mathrm{x})$. [C] acentuado infiltrado linfocitário na submucosa traqueal (seta grossa) e epitélio ciliar normal (seta fina). HE $(200 x)$.

possivelmente foi favorecido, pela idade dos animais utilizados, por fatores ambientais e pela infecção intensa que acometia esses ratos, sendo compatível com outro relato [27]. Para os padrões sanitários mencio- 
nados nesse trabalho e, na ausência de outros métodos, o exame anatomopatológico pode ser utilizado para o diagnóstico da MRM.

No Brasil, o uso de ratos de colônias convencionais em pesquisas é frequiente, havendo a possibili- dade de patógenos responsáveis por infecções inaparentes, estarem interferindo em resultados experimentais com esses animais e tornando anti-econômica a manutenção dessas criações, pela queda de produção e a alta taxa de mortalidade.

\section{REFERÊNCIAS}

1 Barreto M.L., Nascimento E.R., Campos C.A.M., Nascimento M.G.F., Lignon G.B., Lira M.L. \& Silva R.G. 2002. Detection of Mycoplasma pulmonis in Laboratory Rats. Brazilian Journal of Microbiology. 33: 260-264.

2 Barreto M.L., Nascimento E.R., Nascimento M.G.F., Campos C.A.M., Lignon G.B., Lira M.L. \& Silva, R.G. 1996. Isolamento de Mycoplasma pulmonis em uma colônia de ratos Hooded Lister, Niterói - RJ. In: Anais do II World Congress on Laboratory Animal Science e V Congresso Brasileiro de Animais de Laboratório (Rio de Janeiro, RJ). p.98.

3 Brunner H., Krauss H., Schaar H. \& Schiefer H. 1979. Electron microscopic studies on the attachment of Mycoplasma pneumoniae to Guinea pig erytrocytes. Infection and Immunity. 24: 906-911.

4 Campos C.A.M., Nascimento E.R., Barreto M.L., Nascimento M.G.F. \& Verícimo M.A. 2000. Revista Brasileira de Medicina Veterinária. 22: 207-209.

5 Cassell G.H. 1982. The pathogenic potential of mycoplasmas: Mycoplasma pulmonis as a model. Review of Infection Diseases. 4: 18-34.

6 Cassell G.H., Davidson M.K., Davis J.K. \& Lindsey J.R. 1983. Recovery and Identification of Murine Mycoplasmas. In: Tully J.G. \& Razin S. (Eds). Methods in Mycoplasmology: Diagnostic Mycoplasmology. New York: Academic Press, pp. $129-142$.

7 Cassell G.H. \& Hill A. 1979. Murine \& other small-animal Mycoplasmas. In: Barile M.F., Razin S., Tully J.G. \& Whitcomb R.F. (Eds). The Mycoplasmas. New York: Academic Press, pp. 235-273.

8 Cassell G.H., Lindsey J.R., Baker H.J. \& Davis J.K. 1979. Mycoplasmal and rickettsias diseases. In: Baker H.J., Lindsey J.R \& Weisbroth S.H. (Eds). The Laboratory Rat. New York: Academic Press, pp.243-269.

9 Cassell G.H., Lindsey J.R. \& Davis J.K. 1981. Respiratory and genital mycoplasmosis of laboratory rodents: implications for biomedical research. Israel Journal of Medical Science. 17: 548-554.

10 Davidson M.K, Davis J.K, Gambill G.P., Cassell G.H \& Lindsey J.R. 1988. Mycoplasmas of Laboratory Rodents. In: Whittford H.W., Rosenbusch R.f. \& Lauerman L.H. (Eds). Mycoplasmosis in animals: Laboratory diagnosis. Ames: Iowa State University Press, pp.39-50.

11 Davidson M.K., Lindsey J.R., Parker R.F., Tully J.G. \& Cassell G.H. 1988. Differences in virulence for mice among strains of Mycoplasma pulmonis. Infection and Immunity. 56: 2156-2162.

12 Jersey G.C., Whitehair C.K. \& Carter G.R. 1973. Mycoplasma pulmonis as the primary cause of chronic respiratory disease in rats. Journal of the American Veterinary Medical Association. 163: 599-604.

13 Klein J. 1979. A Sentimental Journal to Bar Harbor: fifty year of the Jackson Laboratory. Immunogenetics. 8: 3-11.

14 Kohn D.F. 1971. Sequential pathogenicity of Mycoplasma pulmonis in laboratory rats. Laboratory Animal Science. 21: 849-855.

15 Kohn D.F. 1971. Bronchiectasis in rats infected with Mycoplasma pulmonis: an electron microscopy study. Laboratory Animal Science. 21: 856-861.

16 Kohn D.F. \& Kirk B.E. 1969. Pathogenicity of Mycoplasma pulmonis in laboratory rats. Laboratory Animal Care. 19: 321-330.

17 Lindsey J.R. \& Cassell G.H. 1973. Experimental Mycoplasma pulmonis infection in pathogen free mice. Models for studying mycoplasmosis of the respiratory tract. American Journal of Pathology. 72: 63-90.

18 Lindsey J.R, Cassel G.H. \& Davidson M.K. 1982. Mycoplasmal and other bacterial diseases of the respiratory system. In: Foster, H. L. \& Fox J. G. (Eds). The Mouse in Biomedical Research. New York: Academic Press, pp. 21-41.

19 Lutsky I.I. \& Organick A.B. 1966. Pneumonia due to mycoplasma in gnotobiotic. I.Pathogenicity of Mycoplasma pneumoniae, Mycoplasma salivarium and Mycoplasma pulmonis for the lungs of conventional and gnotobiotic mice. Journal of Bacteriology. 92: 1154-1163. 
20 Manchee R.J. \& Taylor-Robinson D. 1969. Studies on the nature of receptors involved in the attachment of tissue culture cells to mycoplasmas. British Journal of Experimental Pathology. 50: 66-75.

21 Martin S.W., Meek A.H. \& Willeberg P. 1994. Veterinary Epidemiology. Principles and methods. Ames: Iowa State University Press, 348p.

22 Nelson, J. B. 1948. The nasal transmission of pleuropneumonia-like organisms in mice and rats. Journal Infection Diseases. 82: 169-176.

23 Organick A.B, Siegesmund K.A \& Lutsky I.I. 1966. Pneumonia due to mycoplasma in gnotobiotic mice. II. Localization of Micoplasma pulmonis in the lungs of infected gnotobiotic mice by electron microscopy. Journal of Bacteriology. 92 : 1164-1176.

24 Razin S. 1981. Mycoplasma: the smallest pathogenic procaryontes. Israel Journal Medical Science. 17: $510-515$.

25 Razin S. 1995. Molecular Properties of Mollicutes: A Synopsis. In: Razin, S. \& Tully, J.G (Eds). Molecular and Diagnostic Procedures in Mycoplasmology. California: Academic Press, pp. 339-347.

26 Rossini A.J., Nikitin T. \& Fuchs H. 1983. Isolamento de Mycoplasma sp. de Rattus sp. Acometidos de pneumonia por doença natural. In: Anais do XII Congresso Latino Americano De Microbiologia \& Congresso Brasileiro de Microbiologia (São Paulo, Brasil). p. 57.

27 Sanchez S., Tyler K., Rozengurt N. \& Lida J. 1994. Comparison a PCR-based diagnostic assay for Mycoplasma pulmonis with traditional detection tecniques. Laboratory Animals. 28: 249-256.

28 Simecka J.W., Davis J.K., Davidson M.K., Ross S.E., Stadtlander C.T.K.H. \& Cassell G.H. 1992. Mycoplasma diseases of animals. In: Mawiloff J.,Echaney M.C. \& Baseman F. (Eds). Mycoplasmas-Molecular Biology and Pathogenesis. New York: Academic Press, pp.391-411.

29 Steiner D.A. \& Brown M.B. 1993. Impact of Experimental genital mycoplasmosis on pregnancy outcome in spragueDawley rats. Infection and Immunity. 2: 633-639.

30 Steiner D.A., Uhl E.W. \& Brown M.B. 1993. In utero transmission of Mycoplasma pulmonis in experimentally infected Sprague-Dawley Rats. Infection and Immunity. 7: 2985-2990.

31 Timenetsky J., Summa M.E.L. \& Lucca R.R. 1992. Mycoplasma pulmonis and Mycoplasma arthritidis in rodents from animal houses. Brazilian Journal of Veterinary Research and Animal Science. 29: 45-50. 
